\title{
Research on Improvement of Utilization of Open Space: Through Demonstration Experiment Focusing on Spatial Elements
}

\author{
Yuka Kimura $^{1}$, Yuichi Sueshige ${ }^{2}$, Eisuke Aoki ${ }^{3}$, Yusuke Inaduka ${ }^{4}$ and Hideaki Takayanagi ${ }^{5}$ \\ 1. Graduate School of Environmental and Information Studies, Tokyo City University, 8-9-18-2405 Todoroki, Setagaya, Tokyo \\ 158-8586, Japan \\ 2. Department of Urban Life Studies, Tokyo City University, 8-9-18-2405 Todoroki, Setagaya, Tokyo 158-8586, Japan \\ 3. NIPPON ENGINEERING CONSULTANTS CO., LA Tower 11F, 11-2 Shintoshin, Chuo, Saitama-shi, Saitama 330-6011, Japan \\ 4. NIPPON ENGINEERING CONSULTANTS CO., LA Tower 11F, 11-2 Shintoshin, Chuo, Saitama-shi, Saitama 330-6011, Japan \\ 5. Department of Urban Life Studies, Tokyo City University, 8-9-18-2405 Todoroki, Setagaya, Tokyo 158-8586, Japan
}

\begin{abstract}
Along with the rise of buildings, a large number of public open spaces have been created for the purpose of mitigating hatching restrictions and the like. However, many of them are used at low levels, and there remain very few known public open spaces. In this research, we set up a resting place to demonstrate the effect of elements and placement in order to obtain knowledge for appropriately managing and utilizing such low use open public spaces. The survey means analyzed the presence/absence of the attraction/retention degree based on the cross-sectional traffic volume by video analysis and a hearing questionnaire survey for the users of the resting place. From the results, we have found that placement methods and effects that exceed the expectation value of each element, regionality, and attachment, occur by continuing experiments.
\end{abstract}

Key words: Public open space, low usage area, rest area, social experiment, spatial element.

\section{Introduction}

\subsection{Background}

In recent years, urban development has been promoted in neighborhoods of metropolitan areas. However, many underutilized lands in land-area consolidation projects were discovered because of the population decline. Moreover, when developing residential spaces in urban areas, such as the revision of the Green Production Law, we are faced with the issue that green space projects should be comprehensively introduced into the area management business $[1,2]$.

Targeting such vacant, low, and unused lands. In order to develop a model of implementation measures that can contribute to community activities of local

Corresponding author: Yuka Kimura, graduate student, research fields: urban and architect planning. residents, various design elements were replaced, and objective evaluations such as staying time, user recognition, and retention were conducted. This research focuses on areas where public green spaces and parks are scarce, and utilizes places and walks that are familiar to citizens, such as land and low/unused land generated in the process of land readjustment projects, etc. The point is to find a way to temporarily maintain it as a resting facility for the elderly [3, 4]. In addition, in the demonstration experiment, we conducted a behavioral survey and survey of pedestrians regarding functions, elements, and placement required for pedestrian rest facilities. From these analyses, we were able to elucidate that the construction model suitable for the location could be clarified experimentally, a portion of which is discussed in this paper. 


\subsection{Purpose}

In this study, we aim to clarify the elements and arrangements that contribute to the effectiveness of a given space in encouraging pedestrians to stop by and stay on the front road, in order to obtain knowledge on properly managing and utilizing low-use open spaces.

We observe the state of users in the study space in a low-use open space, study the effect of each design element, and examine the model of the practical policy in the low-use land.

\subsection{Overview}

In this experiment, we swap various design elements to plan a practical policy model for low-use areas in order to contribute to the effective use of low, unused land. We objectively evaluate the following four items: contact type, recognition/fixation level, stay status, and continuity.

\section{Research Method}

\subsection{Survey Site}

Fig. 1 shows survey sites which are usually used for parking. For pedestrians along the front road, the reactions to various elements (Table 1) installed on the site were recorded by fixed point observation using a digital video camera [5].

\subsection{Survey Schedule}

We conducted surveys at this survey site on $5 / 23$, $6 / 13,7 / 4,7 / 11,9 / 19,10 / 10,10 / 17,10 / 31$ in 2018 .

Every survey was conducted from 10 AM to 4 PM on Wednesdays. We did not carry out surveys on rainy days.

\subsection{Survey Schedule}

The survey method was shown in Fig. 2.

Method 1: Fixed Point Survey

A single point-of-view observation using digital video cams was conducted during the survey period.

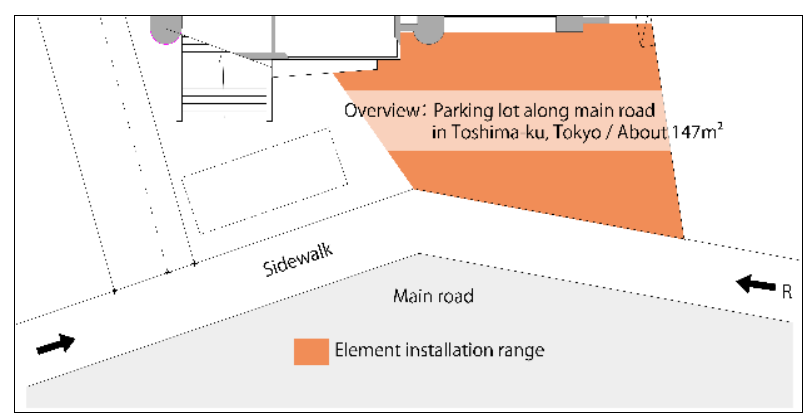

Fig. 1 Site map of the study area.

Table 1 List of installed.

\begin{tabular}{|c|c|c|c|}
\hline & E lem ent & D im ensions & \\
\hline \multirow{3}{*}{ Attracting } & B arga in W agon Type $P$ lanting & & Seed $\mathrm{p}$ lanting tria $120 \%$, Expectations for tra in ing \\
\hline & C ross Is land Type $P$ lanting & & Seed $p$ lanting trial $20 \%$, Expectations for tra in ing \\
\hline & Terraced Is land Type $P$ lanting & & Seed $\mathrm{p}$ lanting tria $120 \%$, Expectations for tra in ing \\
\hline \multirow{5}{*}{ Stay } & 4-seat tab le & $770 \times 1330 \times 710(\mathrm{~mm})$ & Resting $\mathrm{p}$ lace \\
\hline & 2-seat tab le & $800 \times 560 \times 720(\mathrm{~mm})$ & Resting $\mathrm{p}$ lace \\
\hline & Palasol & $3000 \times 2460(\mathrm{~mm})$ & Sunshade, Resting $\mathrm{p}$ lace \\
\hline & A rtific ia I grass $\mathrm{A}$ & $3000 \times 3000(\mathrm{~mm})$ & C ircu lar, E ffect of R e laxation \\
\hline & A rtific ia I grass B & $3000 \times 3000(\mathrm{~mm})$ & Square, Effect of Re laxation \\
\hline \multirow{4}{*}{$\begin{array}{l}\text { L ine-of- } \\
\text { S ight } \\
\text { Control }\end{array}$} & Potted trees L & $1100(\mathrm{~mm})$ & Pak ila, H ong Kong Kapok, E ffect of Re laxation \\
\hline & Potted trees M & $700(\mathrm{~mm})$ & C rest, S ilk jasm ine, Effect of Re laxation \\
\hline & S ignboard A & $870(\mathrm{~mm})$ & P ro ject recogn ition \\
\hline & S ignboard B & $870(\mathrm{~mm})$ & P ro ject recogn ition \\
\hline
\end{tabular}

Attracting element: spatial element that is installed for the purpose of directing attention to the target area (direct-view event); Stay element: spatial element installed for the purpose of stopping at the target site (stop event). 


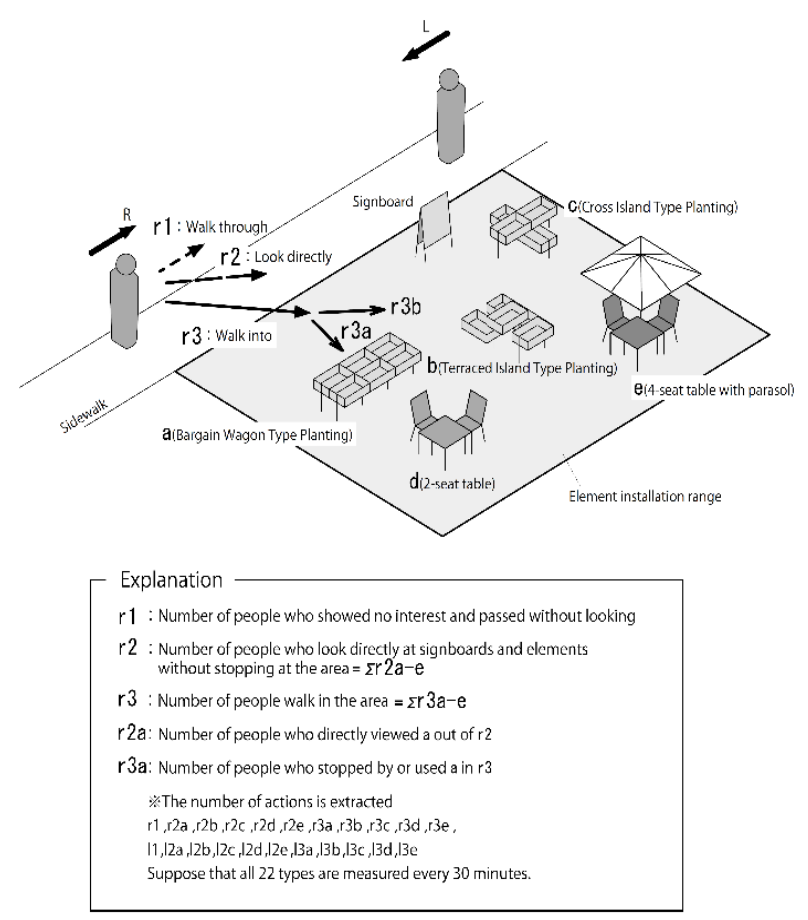

Fig. 2 Defining elements in behavioral surveys.

The presence/absence of attraction and retention was investigated based on cross-sectional traffic volume.

Method 2: Hearing Survey

Interviews and questionnaires to visitors by investigators (questions on cognition, repeat rate, attachment, expectation, creativity, etc.).

Method 3: Environmental Survey

Measure temperature, wind speed, and noise using a measuring instrument.

\subsection{Installed Element}

As shown in Table 1, two types of three elements, namely, an attracting element, a staying element, and a line-of-sight control element, were installed.

\section{Consideration of Direct-View Events on Site and Layout Elements}

An experiment was carried out based on the research method described in Section 2, and an analysis was conducted according to the behavior of pedestrians walking in front. In this section, we focus on the person who looks directly at the site and layout elements among the pedestrians on the front walkway. Table 3 and Fig. 4 show the results of walker behavior measurement.

An analysis was conducted according to $\mathrm{r} 2 \mathrm{a} \cdot \mathrm{r} 2 \mathrm{~b} \cdot \mathrm{r} 2 \mathrm{c}$ in Fig. 3, focusing on the ratio of passersby to the attracting element. As a result, we found that pedestrians tend to look at the one closest to them, regardless of size. In addition, when comparing the planting with the table, the planting gathered more attention than the table. From this, the planting can be considered an element that contributes to attracting.

Next, an analysis was conducted according to $\mathrm{r} 2 \mathrm{~d}$ (1) $\cdot \mathrm{r} 2 \mathrm{~d}(2) \cdot \mathrm{r} 2 \mathrm{e}$ in Fig. 3, focusing on the percentage of passersby who looked at the stay elements. The table with parasols gathered the most attention throughout the experiment. One factor is the presence of elements.

\section{Consideration of Drop-In to Site and Layout Elements}

Continuing from Section 3, this section focuses on those who walked to resting areas among pedestrians on the front walkway. Table 3 and Fig. 5 show the results of walker behavior measurement.

First, we focused on the number of passersby who visited the attracting element and analyzed it. According to the figures of the 1st to the 5th experiments in Fig. 3, the terraced island type planting, which was located closest to the sidewalk and was easily accessible, had the highest number of stops. There were many other cases where people stopped by looking at the flowers without taking a break. In addition, there were cases where they enjoyed conversations with flower-lovers. From this, the attracting element can also create communication between others in a short time, and will be an element that contributes to their stay.

\section{Findings from the Entire Experiment}

\subsection{Evaluation of Continuous Experiments}


In this section, we focused on the recognition in the area by continuing experiments on the same site.

We then interviewed and analyzed the passersby as to whether they had seen the project site before. The rate of recognition increased from $0 \%$ to $27 \%$ in the 1 st to the 4 th rounds, but dropped to $18 \%$ in the 5 th round.

After that, the 6th to 8 th recognition rate stabilized at about $30 \%$, and all of them answered that they had seen it before. Between the 4 th and the 5 th rounds, the two-month period was vacant, and the recognition rate dropped; it became clear that the recognition rate was maintained by regular holding.

Moreover, after the 6th experiment, we interviewed four users who had some reaction in the experiment site or regular users who became acquainted through the experiment. Table 2 shows the results. From this, we can see that every time they see a resting place, they are somewhat interested, confirming the recognition and attachment of local residents and users. Fig. 3 shows the hearing results for changes to repeaters.

\subsection{Thoughts about Increasing the Accuracy of Utilization}

In this section, we continued to experiment and investigate the needs. Main items that gathered the needs were sales of drinks, greenery, seating capacity, and fashionable items. However, with regard to sales and the number of seats, the ideal standard has been polarized, so it is important to adjust it to a standard that many people are satisfied with.

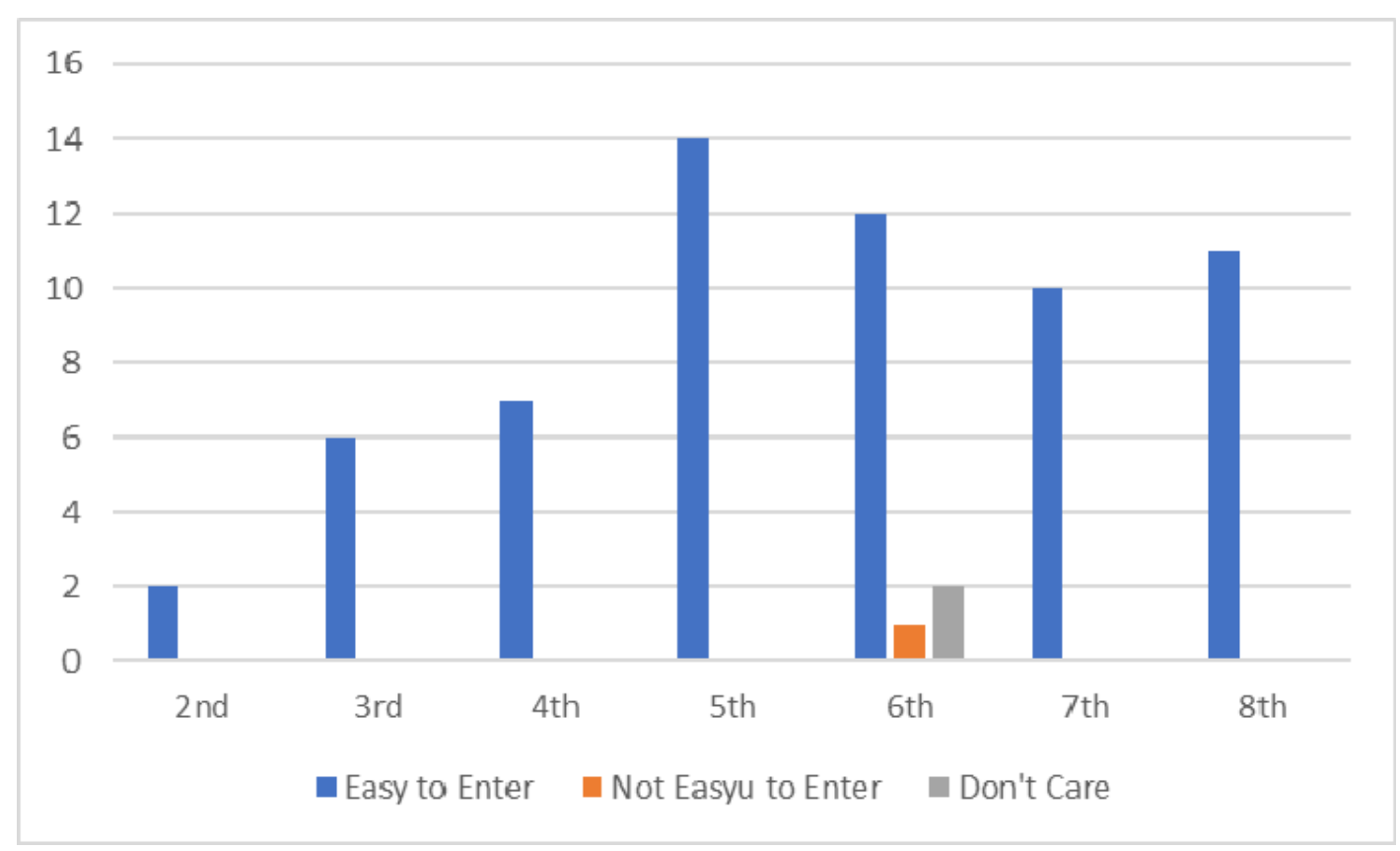

Fig. 3 Reply result as to whether it is easy to enter when there is person in site. 


\section{Research on Improvement of Utilization of Open Space: Through Demonstration Experiment Focusing on Spatial Elements}

Table 2 Survey results on attachment.

\begin{tabular}{|c|c|c|c|c|}
\hline \multirow{4}{*}{$A$} & Sex & Age & Dwelling & Remarks \\
\hline & Male & $30 s$ & Tokyo & $\begin{array}{c}\text { He sometimes comes to Komagome at work. } \\
\text { The last time he didn't want to stop } \\
\text { by the sun. " }\end{array}$ \\
\hline & $\begin{array}{r}\text { Have yc } \\
\text { changes of }\end{array}$ & $\begin{array}{l}\text { iced } \\
\text { space? }\end{array}$ & \multicolumn{2}{|c|}{ What did you think about changes of open space? } \\
\hline & \multicolumn{2}{|c|}{ No } & \multicolumn{2}{|c|}{$\begin{array}{l}\text { He dones't know what has changed, but it's fine } \\
\text { if the sun goes down from the previous time for him. }\end{array}$} \\
\hline \multirow{4}{*}{$B$} & Sex & Age & Dwelling & Remarks \\
\hline & Female & $80 \mathrm{~s}$ & Komagome & $\begin{array}{c}\text { She often walks in front of open spaces } \\
\text { when going to study. }\end{array}$ \\
\hline & $\begin{array}{r}\text { Have yc } \\
\text { changes of }\end{array}$ & $\begin{array}{l}\text { iced } \\
\text { space? }\end{array}$ & \multicolumn{2}{|c|}{ What did you think about changes of open space? } \\
\hline & \multicolumn{2}{|c|}{ Yes } & \multicolumn{2}{|c|}{ She felt that the rest area was getting better and better. } \\
\hline \multirow{4}{*}{ C } & Sex & Age & Dwelling & Remarks \\
\hline & Female & $30 s$ & Tokyo & $\begin{array}{l}\text { Her workplace was in Komagome and she } \\
\text { often saw a rest area. }\end{array}$ \\
\hline & $\begin{array}{r}\text { Have yc } \\
\text { changes of }\end{array}$ & $\begin{array}{l}\text { iced } \\
\text { space? }\end{array}$ & \multicolumn{2}{|c|}{ What did you think about changes of open space? } \\
\hline & \multicolumn{2}{|c|}{ No } & \multicolumn{2}{|c|}{$\begin{array}{l}\text { I didn't notice a change in the rest area, but every time } \\
\text { I saw it, I thought I was doing something strange. }\end{array}$} \\
\hline \multirow{4}{*}{ D } & Sex & Age & Dwelling & Remarks \\
\hline & Female & $70 \mathrm{~s}$ & Komagome & $\begin{array}{l}\text { She runs a cleaning shop nearby. } \\
\text { I stopped by every time during the } \\
\text { experiment and helped with the flowers. }\end{array}$ \\
\hline & $\begin{array}{r}\text { Have yc } \\
\text { changes of }\end{array}$ & ticed & \multicolumn{2}{|c|}{ What did you think about changes of open space? } \\
\hline & \multicolumn{2}{|c|}{ Yes } & \multicolumn{2}{|c|}{$\begin{array}{c}\text { She came to visit because she was worried about the lack } \\
\text { of flower soil. It was good that the soil was added } \\
\text { properly in the next experiment that } \\
\text { said there was little soil. } \\
\text { In addition to placing flowers, the layout may be devised. } \\
\text { Also, the planting is very good. } \\
\text { We want you to make beautiful flower bed from now on. }\end{array}$} \\
\hline
\end{tabular}

Table 3 List of usage status of installation elements.

\begin{tabular}{|c|c|c|c|c|c|c|c|c|c|c|c|c|c|c|c|c|c|c|c|c|c|c|c|c|c|}
\hline \multirow{2}{*}{ Action type } & \multicolumn{3}{|c|}{ 1st round $(5 / 13)$} & \multicolumn{3}{|c|}{ 2nd round $(6 / 13)$} & \multicolumn{3}{|c|}{3 rd round $(7 / 4)$} & \multicolumn{3}{|c|}{4 th round $(7 / 11)$} & \multicolumn{3}{|c|}{ 5th round $(9 / 11)$} & $\gamma$ & \multicolumn{3}{|c|}{6 th round $(10 / 3)$} & \multicolumn{6}{|c|}{\begin{tabular}{|l|l|l}
7 th round $(10 / 10)$ & 8 th round $(10 / 31)$
\end{tabular}} \\
\hline & \multirow{2}{*}{\begin{tabular}{|c|}
$\begin{array}{c}\text { Real } \\
\text { num ber }\end{array}$ \\
478
\end{tabular}} & \multicolumn{2}{|c|}{ Percentage } & \multirow{2}{*}{$\begin{array}{c}\begin{array}{c}\text { Real } \\
\text { num ber }\end{array} \\
1150\end{array}$} & \multicolumn{2}{|c|}{ Percentage } & \multirow{2}{*}{\begin{tabular}{|l|}
$\begin{array}{c}\text { Real } \\
\text { num ber }\end{array}$ \\
1215
\end{tabular}} & \multicolumn{2}{|c|}{ Percentage } & \multirow{2}{*}{\begin{tabular}{|c|}
$\begin{array}{c}\text { Real } \\
\text { num ber }\end{array}$ \\
1199 \\
\end{tabular}} & \multicolumn{2}{|c|}{ Percentage } & \multirow{2}{*}{\begin{tabular}{|c|c|}
$\begin{array}{c}\text { Real } \\
\text { num ber }\end{array}$ \\
1395
\end{tabular}} & \multicolumn{2}{|c|}{ Percentage } & \multirow{2}{*}{\begin{tabular}{|r|} 
Action type \\
1
\end{tabular}} & \multirow{2}{*}{\begin{tabular}{|l|}
$\begin{array}{c}\text { Real } \\
\text { num ber }\end{array}$ \\
1441
\end{tabular}} & \multicolumn{2}{|c|}{ Percentage } & \multirow{2}{*}{\begin{tabular}{|c|}
$\begin{array}{c}\text { Real } \\
\text { num ber }\end{array}$ \\
1573
\end{tabular}} & \multicolumn{2}{|c|}{ Percentage } & \multirow{2}{*}{\begin{tabular}{|c|}
$\begin{array}{c}\text { Real } \\
\text { num ber }\end{array}$ \\
1816
\end{tabular}} & \multicolumn{2}{|c|}{ Percentage } \\
\hline 1 & & & $57 \%$ & & & $44 \%$ & & & $40 \%$ & & & $42 \%$ & & & $43 \%$ & & & & $39 \%$ & & & $44 \%$ & & & $46 \%$ \\
\hline $2 \mathrm{a}$ & 84 & $23 \%$ & & 164 & $12 \%$ & & 195 & $11 \%$ & & 117 & $7 \%$ & & 129 & $7 \%$ & & $2 \mathrm{a}$ & 497 & $23 \%$ & & 471 & $24 \%$ & & 567 & $27 \%$ & \\
\hline $2 b$ & 228 & $63 \%$ & & 814 & $58 \%$ & & 836 & $47 \%$ & & 634 & $38 \%$ & & 1001 & $55 \%$ & & $2 b$ & 0 & $0 \%$ & & 0 & $0 \%$ & & 531 & $25 \%$ & \\
\hline $2 c$ & 1 & $0 \%$ & & 135 & $10 \%$ & & 483 & $27 \%$ & & 540 & $33 \%$ & & 236 & $13 \%$ & & $2 c$ & 696 & $32 \%$ & & 731 & $37 \%$ & & 290 & $14 \%$ & \\
\hline \multirow[t]{2}{*}{$2 d$} & 3 & $1 \%$ & & 74 & $5 \%$ & & 79 & $4 \%$ & & 176 & $11 \%$ & & 130 & $7 \%$ & & $2 \mathrm{~d}(1)$ & 511 & $24 \%$ & & 319 & $16 \%$ & & 97 & $5 \%$ & \\
\hline & & & & & & & & & & & & & & & & $2 \mathrm{~d}(2)$ & 3 & $0 \%$ & & 3 & $0 \%$ & & 190 & $9 \%$ & \\
\hline \multirow{2}{*}{$\begin{array}{r}2 \mathrm{e} \\
2\end{array}$} & 46 & $1 \%$ & & 228 & $16 \%$ & & 203 & $11 \%$ & & 188 & $11 \%$ & & 322 & $18 \%$ & & $2 \mathrm{e}$ & 453 & $21 \%$ & & 470 & $24 \%$ & & 419 & $20 \%$ & \\
\hline & 362 & & $43 \%$ & 1415 & & $54 \%$ & 1796 & & $59 \%$ & 1655 & & $57 \%$ & 1818 & & $56 \%$ & 2 & 2160 & & $59 \%$ & 1994 & & $55 \%$ & 2094 & & $53 \%$ \\
\hline $3 a$ & 2 & $33 \%$ & & 1 & $3 \%$ & & 8 & $15 \%$ & & 1 & $4 \%$ & & 0 & $0 \%$ & & $3 \mathrm{a}$ & 3 & $6 \%$ & & 1 & $3 \%$ & & 1 & $3 \%$ & \\
\hline $3 b$ & 1 & $17 \%$ & & 14 & $42 \%$ & & 17 & $32 \%$ & & 14 & $52 \%$ & & 16 & $26 \%$ & & $3 b$ & 0 & $0 \%$ & & 0 & $0 \%$ & & 0 & $0 \%$ & \\
\hline $3 c$ & 2 & $33 \%$ & & 4 & $12 \%$ & & 4 & $8 \%$ & & 4 & $15 \%$ & & 6 & $10 \%$ & & $3 c$ & 13 & $26 \%$ & & 4 & $13 \%$ & & 2 & $6 \%$ & \\
\hline $3 d$ & 0 & $0 \%$ & & 1 & $3 \%$ & & 8 & $15 \%$ & & 6 & $22 \%$ & & 26 & $42 \%$ & & $3 \mathrm{~d}$ (1) & 15 & $30 \%$ & & 2 & $6 \%$ & & 11 & $34 \%$ & \\
\hline & & & & & & & & & & & & & & & & $3 d(2)$ & 4 & $8 \%$ & & 5 & $16 \%$ & & 2 & $6 \%$ & \\
\hline $3 \mathrm{e}$ & 1 & $17 \%$ & & 13 & $39 \%$ & & 16 & $30 \%$ & & 2 & $7 \%$ & & 14 & $23 \%$ & & $3 \mathrm{e}$ & 15 & $30 \%$ & & 19 & $61 \%$ & & 16 & $50 \%$ & \\
\hline 3 & 6 & & $1 \%$ & 33 & & $1 \%$ & 53 & & $2 \%$ & 27 & & $1 \%$ & 62 & & $2 \%$ & 3 & 50 & & $1 \%$ & 31 & & $1 \%$ & 32 & & $1 \%$ \\
\hline Total $(1+2+3)$ & 846 & & & 2598 & & & \begin{tabular}{|l|}
3064 \\
\end{tabular} & & & 2881 & & & 3275 & & & Tota $(1+2+3)$ & \begin{tabular}{|l|}
3651 \\
\end{tabular} & & & 3598 & & & 3942 & & \\
\hline
\end{tabular}





Fig. 4 List of direct view rates.
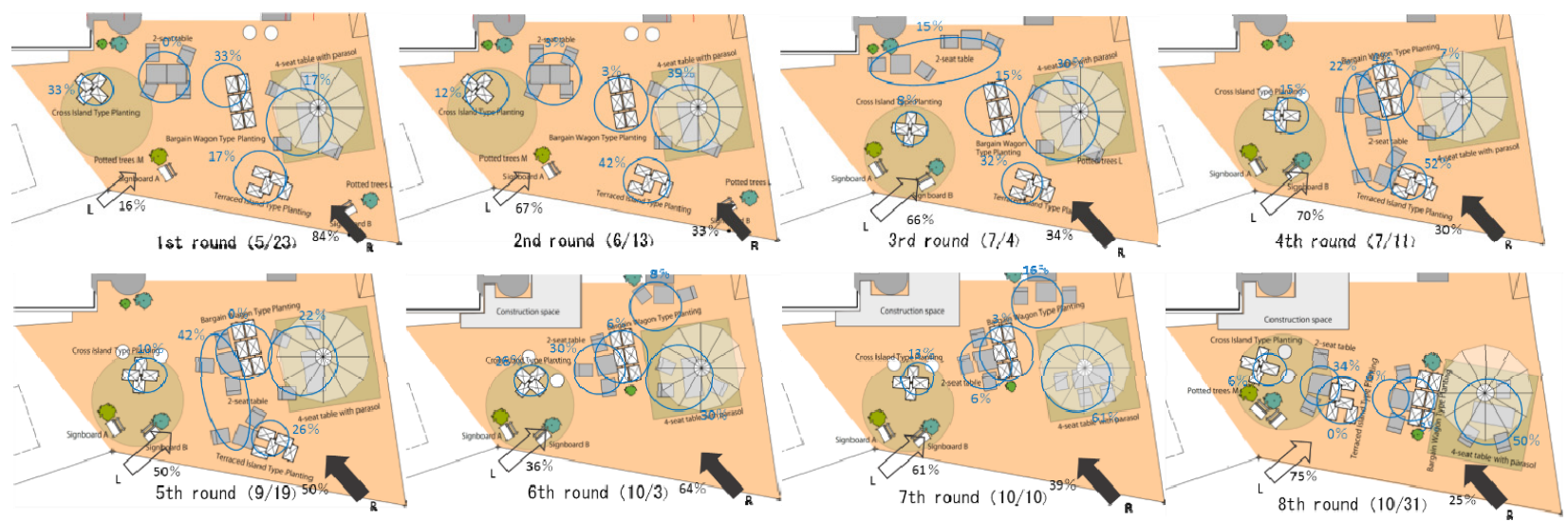

Fig. 5 List of walking into rates.

\section{Conclusion}

First, it can be said that the following three items are important in the attracting elements: the elements in the space that have the effect of stimulating the senses and sensibility, the installation of elements with a presence that can be used as landmarks, and the usage situation that can be seen from the outside. For stay elements, it is important to accurately inform the pedestrian of the arrangement of tables that create a variety of usage methods, the securing of personal areas, the arrangement of elements that create communities, and the purpose of implementation. The findings from all experiments revealed that the number of elements that stopped by and the number of elements that stopped looking at were not proportional. The recognition/attachment of continuing experiments,

and the importance of the interval between experiment dates were also shown.

In future research, it is necessary to clarify whether this effect is produced even if the target site changes, or whether the results are limited by research limit points.

\section{References}

[1] Izumiya, R., Nakano, T., and Nemoto, H. 2016. "The Activity Evaluation Method of Public Space by the Human Oriented Perspective-Focusing on Activity Investigation of 'IKEBUKURO East Green Boulevard Sidewalk Cafe Pilot Project in 2015 Spring'." J. Archit. Plann. 81 (730): 2763-73.

[2] Izumiya, R., Akiyama, H., and Kobayashi, M. 2015. "Study on the Application and Management of 'Privately Owned Public Spaces' in the Urban Central Area-Through Research and Analysis to Community Management Organization Registration System the 


\section{Focusing on Spatial Elements}

Tokyo Municipal Ordinance on Promoting the Creation SYARETA-MACHINAMI of Tokyo." J. Archit. Plann. 80 (710): 915-22.

[3] Ministry of Land, Infrastructure and Transport. 2007. Interim Report on Low/Unused Land Countermeasures Subcommittee.
[4] Ministry of Land, Infrastructure and Transport. 2008. Utilization and Management of Low and Unused Land.

[5] Kawamoto, Y., and Nakajima, N. 2016. "Local Government's Original Standard for Permission of Occupancy in Privately Owned Public Spaces." AIJ J. Technol. Des. 22 (52): 1127-30. 